\title{
Real Balance Effects, Timing and Equilibrium Determination
}

\section{Christian Stoltenberg*}

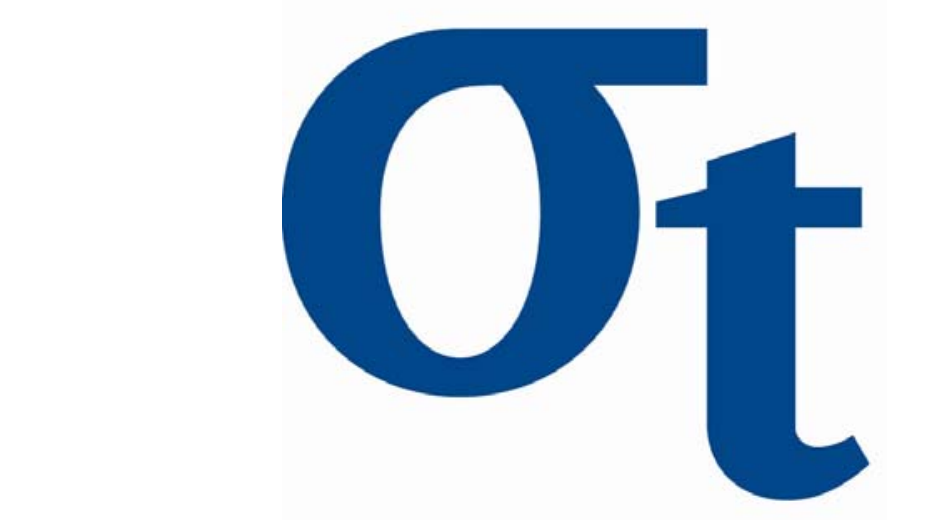

* Department of Economics, Humboldt-Universität zu Berlin, Germany

$\underline{v}$

u

$\bar{\Upsilon}$

This research was supported by the Deutsche Forschungsgemeinschaft through the SFB 649 "Economic Risk".

http://sfb649. wiwi. hu-berlin.de ISSN 1860-5664 


\title{
Real Balance Effects, Timing and Equilibrium Determination*
}

\author{
Christian Stoltenberg ${ }^{\dagger}$
}

October 9, 2006

\begin{abstract}
This paper examines whether the existence and the timing of real balance effects contribute to the determination of the absolute price level, as suggested by Patinkin $(1949,1965)$, and if they affect conditions for local equilibrium uniqueness and stability. I show that there exists a unique price level sequence that is consistent with an equilibrium under interest rate policy, only if beginning-ofperiod money yields transaction services. Predetermined real money balances can then serve as a state variable, implying that interest rate setting must be passive a violation of the Taylor-principle - for unique, stable, and non-oscillatory equilibrium sequences. On the contrary, when the end-of-period money stock facilitates transactions, the equilibrium displays nominal indeterminacy and equilibrium uniqueness requires an interest rate setting consistent with the Taylor-principle.
\end{abstract}

JEL classification: E32, E41, E52.

Keywords: Real balance effects, predetermined money, price level determination, real determinacy, monetary policy rules, flexible prices.

*I'm especially thankful to Harald Uhlig, Jordi Galí, Andreas Schabert and Mark Weder for helpful discussions. Further, I would like to thank Michael Burda, Fabio Canova, Bartosz Mackowiak, Emanuel Mönch, Marco Airaudo and Matthias Paustian for suggestions and comments. This research was supported by the Deutsche Forschungsgemeinschaft through the SFB 649 "Economic Risk". This research project is part of the unpublished working paper "Money Demand and Macroeconomic Stability Revisited" (joint with Andreas Schabert).

${ }^{\dagger}$ Humboldt University Berlin, Department of Economics, D-10178 Berlin, Germany, email: stoltenb@wiwi.hu-berlin.de, fax: +49 30 2093-5934, tel: +49/30/2093-5935. 


\section{Introduction}

The conduct of monetary and fiscal policy is known to affect the determination of the price level and, under non-neutrality, the real equilibrium allocation. While previous contributions to this line of research have primarily considered monetary policy regimes that are characterized by constant money growth (see, e.g., Obstfeld and Rogoff, 1983, and Matsuyama, 1990, 1991), recent studies mainly focus on policy regimes summarized by interest rate feedback rules, such as Taylor (1993), Benhabib et al. (2001a, 2001b, 2003), Carlstrom and Fuerst (2001) or Bénassy (2000). Correspondingly, researchers nowadays pay less attention to the role of monetary aggregates and increasingly employ money demand specifications that allow to neglect money for the analysis of equilibrium determination (see Dupor, 2001, Woodford, 2003, or Carlstrom and Fuerst, 2004). Given that fiscal solvency is guaranteed under all possible circumstances, there are two prominent results in this literature. First, the equilibrium allocation is neutral with respect to the absolute price level (nominal indeterminacy). Second, the Taylor-principle ensures stability and uniqueness of equilibrium sequences. According to the Taylor-

principle (activeness), monetary policy should aggressively fight inflation by raising the nominal interest rate more than the increase in inflation.

In this paper, I examine whether these prominent findings are robust to different specifications of money demand, when prices are completely flexible. To be more precise, I revisit the role of real balance effects and their timing for equilibrium determination, the determination of the absolute price level and for uniqueness and stability of equilibrium sequences. I show, that if the beginning-of-period stock of money facilitates transactions and interest rate policy is contingent on current inflation, then predetermined real money balances can restrict current consumption in every period under interest rate policy. I.e. predetermined real money balances can serve as an endogenous state variable of the economy, a key role of real money, which has been dis- 
regarded in the literature. ${ }^{1}$ In this case, a perfect foresight equilibrium displays nominal determinacy: it is is associated with a unique price level sequence. Interest rate policy should then rather be passive than active - a violation of the Taylor-principle - to avoid oscillatory or explosive equilibrium sequences, such that a perfect foresight equilibrium is uniquely determined (real determinacy). Notably, the unique determination of the price level and the uniqueness of equilibrium sequences are 2 sides of the same coin. If real money is a state variable, then the whole set of equilibrium sequences is indexed with a particular value for initial real money balances, which results in a particular initial value for the price level, since initial nominal balances are given. Working forward, this mechanism pins down uniquely the complete set of sequences for the absolute price level and nominal balances under interest policy.

I set up a discrete time general equilibrium model with flexible prices, where real money balances and consumption enter the utility function in a non-separable way, that is consistent with a shopping time technology (McCallum and Goodfriend, 1987). ${ }^{2}$ I apply two different specifications about the particular stock of money, that enters the utility function: Either the stock of money at the beginning or at the end of the period is assumed to yield transaction services. The former specification corresponds to Svensson's(1985) timing of markets within one period, where the goods market is closed, before the asset market is opened. Then, households rely on the stock of money carried over from the previous period for transactions in the goods market. This formulation is applied for example in Woodford (1990), McCallum and Nelson (1999) or more recently in Persson, Persson and Svensson (2006). The second specification, which can be found

\footnotetext{
${ }^{1}$ This property marks a main difference of my framework to the specifications in Carlstrom and Fuerst, 2001, who show that different assumptions of the timing of markets can affect the conditions (real) equilibrium determinacy under interest rate rules.

${ }^{2}$ Feenstra (1986) and Brock (1974) show that a MIU formulation can be equivalent to more explicit formulations of transaction frictions such as cash-in-advance constraints, real resource costs of transactions or shopping time specifications. For an exact equivalence, real money balances and consumption should enter the utility function in a non-separable way.
} 
in Woodford (2003) or Sargent and Ljungqvist (2004), can be interpreted as a short-cut for a reverse timing of markets. I.e. households can always adjust their money holdings to facilitate transactions. The resulting real balance effects are commonly neglected, since they are typically found to be very small (Lucas, 2000 or Ireland, 2004). I show, that the existence and the timing of real balance effects (not the magnitude) can have substantial implications for equilibrium determination.

Under real balance effects and interest rate policy, a uniquely determined price level is associated with real money being a relevant state variable and, thus, with a history dependent evolution of equilibrium sequences, which crucially affects the conditions for macroeconomic stability. This property has been disregarded in related studies where money demand specifications are applied which relate to my end-of-period version (see Benhabib et al., 2001a, Carlstrom and Fuerst, 2001, or Woodford, 2003). Throughout the analysis of stability and uniqueness of equilibrium sequences, I take into account that (stable) equilibrium sequences can be non-oscillatory or oscillatory. This distinction is important since stable but oscillatory equilibrium sequences can hardly be viewed as recommendable for a central bank that aims to stabilize the economy. The main principles for equilibrium determination and stability under simple monetary policy feedback rules and can be summarized as follows.

- For the unique determination of a rational expectations equilibrium and a consistent price level sequence, i.e., for real and nominal determinacy, beginning-ofperiod money has to enter the utility function, and interest rate policy has to respond to current inflation. Neither an interest rate peg nor a forward looking interest rate rule lead to this result.

- Under the beginning-of-period specification, an interest rate policy that reacts to changes in current inflation has to be passive for equilibrium sequences to be 
uniquely determined and to converge to the steady state in a non-oscillatory way.

- If the end-of-period specification applies or expected future inflation serves as the policy indicator, real balance effects turn out to be (almost) negligible for equilibrium determination: The perfect foresight equilibrium is consistent with any price level sequence, and the Taylor-principle is necessary for stability and uniqueness of equilibrium sequences.

- Under a constant money growth regime, a perfect foresight equilibrium displays nominal determinacy, but real money does not serve as a relevant state variable. Remarkably, for the economy to evolve in a history dependent way, it does not suffices, that monetary policy is history dependent. Equilibrium sequences are, in any case, locally stable and uniquely determined. ${ }^{3}$

While these results are derived for the case where the labor supply elasticity is finite, I further show that the assumption of an infinitely elastic labor supply, which is for example made in Dupor (2001), or Carlstrom and Fuerst (2004), for a related purpose, is not harmless for the local equilibrium properties under interest rate policy. For example, I find that an equilibrium under interest rate policy and flexible prices is then consistent with any initial price level, and that the well-established principles for equilibrium uniqueness for a separable utility function (see Woodford, 2003) apply when end-of-period money provides utility.

The remainder of the paper is organized as follows. Section 2 develops the model. Section 3 analyzes nominal and real determinacy under flexible prices. In the first part, I consider the case where the beginning-of-period stock of money provides utility, while the results for the end-of-period specification are briefly summarized in the second

\footnotetext{
${ }^{3}$ This result relies on real balance effects to imply consumption and real balances to be Edgeworthcomplements. When they are Edgeworth-substitutes, constant money growth can also lead to real indeterminacy, as shown by Carlstrom and Fuerst (2003).
} 
part. ${ }^{4}$ For both specifications, I derive the implications for equilibrium determination and local stability under current and forward looking interest rate rules, and for money growth rules. The last part of section 3 discusses my findings and compares them to results in related studies. In section $4 \mathrm{I}$ list the main results when prices are set in a staggered way. ${ }^{5}$ Section 5 concludes.

\section{The model}

In this section an infinite horizon general equilibrium model with representative agents and perfectly flexible prices is developed. I consider a money in the utility function specification that leads to real balance effects and assume either that the stock of money at the beginning or at the end of the period yields transaction services. Monetary policy is either specified in form of an interest rate feedback rule or constant money growth. To check for the robustness of the results for the former policy regime, I apply contemporaneous and forward looking interest rate rules.

Lower (upper) case letters denote real (nominal) variables. There is a continuum of identical and infinitely lived households. At the beginning of period $t$, households' financial wealth comprises money $M_{t-1}$ and nominally non-state contingent government bonds $B_{t-1}$ carried over from the previous period. The households' budget constraint reads

$$
M_{t}+B_{t}+P_{t} c_{t} \leq R_{t-1} B_{t-1}+M_{t-1}+P_{t} w_{t} l_{t}-P_{t} \tau_{t}
$$

$c_{t}$ denotes consumption, $P_{t}$ the aggregate price level, $w_{t}$ the real wage rate, $l_{t}$ working time, $\tau_{t}$ a lump-sum tax, and $R_{t}$ the gross nominal interest rate on government

\footnotetext{
${ }^{4}$ My findings for the latter case relate to the results in Benhabib et al. (2001a), Carlstrom and Fuerst (2001), and Woodford (2003)

${ }^{5}$ The details of this analysis can be found in an accompanying working paper version, Schabert and Stoltenberg (2005).
} 
bonds. Further, households have to fulfill the no-Ponzi game condition, $\lim _{t \rightarrow \infty}\left(m_{t}+\right.$ $\left.b_{t}\right) \prod_{i=1}^{t} \pi_{i} / R_{i-1} \geq 0$. The objective of the representative household is

$$
\sum_{t=0}^{\infty} \beta^{t} u\left(c_{t}, l_{t}, A_{t} / P_{t}\right), \quad \beta \in(0,1)
$$

$\beta$ denotes the subjective discount factor and $A_{t}$ nominal balances, which will be defined below. The instantaneous utility function is assumed to satisfy

$$
\begin{aligned}
& u_{c}>0, u_{l}<0, u_{a}>0, u_{c c}<0, u_{a a}<0, u_{l l} \leq 0 \\
& u_{c a}>0, u_{c l}=u_{a l}=0, u_{c c} u_{a a}-u_{c a}^{2}>0
\end{aligned}
$$

and the usual Inada-conditions, where $a_{t}=A_{t} / P_{t}$. According to (4) the cross derivative $u_{c a}$ is (strictly) positive, such that marginal utility of consumption rises with real money balances. The resulting properties, i.e., non-separability and real balance effects, typically emerge under more explicit specifications of transaction frictions. As, for example, shown by Brock (1974) or Feenstra (1986), a money-in-the-utility (MIU) function specification, which is equivalent to a specification where purchases of consumption goods are associated with transaction costs that are either measured by shopping time or real resources, is usually characterized by these properties. To be more precise, introducing these transaction frictions in a corresponding model with a utility function $v\left(c_{t}, 1-l_{t}\right)$ would lead to real balance effects, which are equivalent to a MIU specification with $u_{c a}>0$, if (but not only if) the labor supply elasticity is finite (see the accompanying working paper version Schabert and Stoltenberg, 2005). It should be noted that an infinite labor supply elasticity will lead to be of particular interest in what follows.

To avoid additional complexities, I assume that the respective cross derivatives are equal to zero $u_{l c}=u_{l a}=0 .{ }^{6}$ The last assumption in (4), $u_{c c} u_{a a}-u_{c a}^{2}>0$, is imposed to

\footnotetext{
${ }^{6}$ This implies that the instantaneous utility function $u\left(c_{t}, a_{t}, l_{t}\right)$ can be written as $f\left(c_{t}, a_{t}\right)-g\left(l_{t}\right)$.
} 
ensure - together with (3) - the utility function to be strictly concave. The conditions in (3)-(4) further ensure that real money balances and consumption are normal goods, i.e. that the utility function exhibits increasing expansion paths with respect to money and consumption.

The variable $A_{t}$ describes the relevant stock of money that provides - in real terms - utility. Throughout the paper, I consider two cases, where $A_{t}$ denotes money either held at the Beginning of the period, $M_{t-1}$, or at the End of period, $M_{t}:^{7}$

$$
A_{t}=\left\{\begin{array}{ll}
M_{t-1} & \text { version } B \\
M_{t} & \text { version } E
\end{array} .\right.
$$

The $B$-version, which, for example, relates to the money-in-the-utility function specifications in Woodford (1990), McCallum and Nelson (1999), and is more recently applied in Persson, Persson and Svensson (2006). It is consistent with Svensson's (1985) timing of markets assumption within one period where the goods market is closed before the asset market is opened. This means that the representative agent in period $t$ relies on the stock of money carried over from the previous period for transactions in the goods market - implying that a surprise inflation directly affects households' utility. On the contrary, in the end-of-period specification ( $E$-version), which can for example be found in Brock (1974), Ljungqvist and Sargent (2004), or Woodford (2003), the stock of money held at the end of the period facilitates transactions. This formulation corresponds to the reverse timing of markets, i.e. the asset market is closed before the goods market is opened.

Maximizing (2) subject to (1) and the no-Ponzi game condition for given initial

\footnotetext{
${ }^{7}$ These specifications are related, but not identical, to those applied in Carlstrom and Fuerst (2001). In particular, they assume that the monetary aggregate, which enters the utility function, is either given by $A_{t}=M_{t-1}+R_{t-1} B_{t}-B_{t}+P_{t} \tau_{t}$ or $A_{t}=M_{t-1}+R_{t-1} B_{t}-B_{t}+P_{t} \tau_{t}-P_{t} c_{t}+P_{t} y_{t}$. As a consequence, money demand can matter for local uniqueness of the equilibrium sequences of inflation and consumption under interest rate policy, even if the utility function is separable.
} 
values $M_{-1}>0$ and $R_{-1} B_{-1} \geq 0$ leads to the following first order conditions for consumption, money, labor supply, and government bonds:

$$
\begin{aligned}
\lambda_{t} & =\left\{\begin{array}{ll}
u_{c}\left(c_{t}, m_{t-1} / \pi_{t}\right) & \text { version } B \\
u_{c}\left(c_{t}, m_{t}\right) & \text { version } E
\end{array},\right. \\
i_{t} \frac{\lambda_{t+1}}{\pi_{t+1}} & =\left\{\begin{array}{ll}
u_{a}\left(c_{t+1}, m_{t} / \pi_{t+1}\right) / \pi_{t+1} & \text { version } B \\
\beta^{-1} u_{a}\left(c_{t}, m_{t}\right) & \text { version } E
\end{array},\right. \\
u_{l}\left(l_{t}\right) & =-w_{t} \lambda_{t}, \\
\lambda_{t} & =\beta R_{t} \lambda_{t+1} \pi_{t+1}^{-1},
\end{aligned}
$$

where $i_{t}=R_{t}-1$ denotes the net interest rate on government bonds, $\lambda_{t}$ denotes a Lagrange multiplier, $\pi_{t}$ the inflation rate $\pi_{t}=P_{t} / P_{t-1}$, and $m_{t}$ real balances $m_{t}=$ $M_{t} / P_{t}$. Note that beginning-of-period real balances $m_{t-1}$ enter the set of first order conditions only in case $B$ and only together with the current inflation rate, implying that in principle, both versions are forward-looking. Nevertheless, I will show below that beginning-of-period real money balances can restrict current consumption, if they serve as a relevant state variable. The optimum is further characterized by the budget constraint (1) holding with equality and by the transversality condition $\lim _{t \rightarrow \infty}\left(m_{t}+\right.$ $\left.b_{t}\right) \prod_{i=1}^{t} \pi_{i} / R_{i-1}=0$.

There is a continuum of perfectly competitive firms of mass one. Firms produce the consumption good $c_{t}$ with the linear technology $y_{t}=l_{l}$. The only production factor labor, supplied by households, is hired on a competitive labor market - implying that profit maximization leads to zero profits and a real wage $w_{t}$ of unity. Total output comprises private consumption.

The public sector consists of a fiscal and a monetary authority. I consider two widely applied specifications for the monetary policy regime. The first regime is characterized 
by the central bank setting the nominal interest rate contingent on current or on future inflation.

$$
R_{t}=\rho\left(\pi_{t}\right), \quad \text { or } \quad R_{t}=\rho\left(\pi_{t+1}\right), \quad \text { with } \rho^{\prime} \geq 0, \quad R_{t} \geq 1
$$

I further assume that the steady state condition $R=\pi / \beta$ has a unique solution for $R>1$. According to the interest rate feedback rule (9), the response of the interest rate to changes in inflation, $\rho_{\pi}$, is non-negative. The second regime, is characterized by the central bank holding the money growth constant $M_{t} / M_{t-1}=\mu$, where $\mu \geq 1$ :

$$
m_{t} \pi_{t} / m_{t-1}=\mu
$$

The fiscal authority issues risk-free one period bonds, receives lump-sum taxes from households, and transfers from the monetary authority. I assume that tax policy guarantees government solvency (ricardian fiscal policy), i.e., ensures $\lim _{t \rightarrow \infty}\left(m_{t}+\right.$ $\left.b_{t}\right) \prod_{i=1}^{t} \pi_{i} / R_{i-1}=0$.

\section{Equilibrium determination under flexible prices}

In this section, I assess how real balance effects, the timing of markets and monetary policy affect the determination of the price level and of the perfect foresight equilibrium. As described in the previous section, I consider two versions of the model which differ with regard to the stock of money that enters the utility function, i.e., the $B$-version and the $E$-version, and I consider three types of monetary policy rules described by (9) or (10). The equilibrium for a positive interest rate $\left(R_{t}>1\right)$ can then be summarized as follows.

Definition 1 Given an initial money endowment $M_{-1}$, a ricardian fiscal policy $\tau_{t} \forall t \geq$ 
0 and a monetary policy (9) or (10), a perfect foresight equilibrium (PFE) consists of set of sequences $\left\{c_{t}, \pi_{t}, m_{t}, R_{t}\right\}_{t=0}^{\infty}$ and a price level $P_{0}$ satisfying

\section{1. for the B-version:}

$$
\begin{gathered}
u_{l}\left(c_{t}\right)=-u_{c}\left(c_{t}, \frac{m_{t-1}}{\pi_{t}}\right) \quad \forall t \geq 1, \\
u_{c}\left(c_{t}, \frac{m_{t-1}}{\pi_{t}}\right)=\beta R_{t} u_{c}\left(c_{t+1}, \frac{m_{t}}{\pi_{t+1}}\right) / \pi_{t+1} \quad \forall t \geq 1, \\
\left(R_{t}-1\right) u_{c}\left(c_{t+1}, \frac{m_{t}}{\pi_{t+1}}\right)=u_{a}\left(c_{t+1}, \frac{m_{t}}{\pi_{t+1}}\right) \quad \forall t \geq 1,
\end{gathered}
$$

and for $t=0$ :

$$
\begin{gathered}
u_{l}\left(c_{0}\right)=-u_{c}\left(c_{0}, \frac{M_{-1}}{P_{0}}\right), \\
u_{c}\left(c_{0}, \frac{M_{-1}}{P_{0}}\right)=\beta R_{0} u_{c}\left(c_{1}, \frac{M_{0}}{P_{1}}\right) / \pi_{1}, \\
\left(R_{0}-1\right) u_{c}\left(c_{1}, \frac{M_{0}}{P_{1}}\right)=u_{a}\left(c_{1}, \frac{M_{0}}{P_{1}}\right),
\end{gathered}
$$

2. for the E-version:

$$
\begin{gathered}
u_{l}\left(c_{t}\right)=-u_{c}\left(c_{t}, m_{t}\right) \quad \forall t \geq 1 \\
u_{c}\left(c_{t}, m_{t}\right)=\beta R_{t} u_{c}\left(c_{t+1}, m_{t+1}\right) / \pi_{t+1} \quad \forall t \geq 1, \\
\left(R_{t}-1\right) u_{c}\left(c_{t+1}, m_{t+1}\right) / \pi_{t+1}=u_{a}\left(c_{t}, m_{t}\right) / \beta \quad \forall t \geq 1,
\end{gathered}
$$

and for $t=0$

$$
\begin{gathered}
u_{l}\left(c_{0}\right)=-u_{c}\left(c_{0}, M_{0} / P_{0}\right), \\
u_{c}\left(c_{0}, M_{0} / P_{0}\right)=\beta R_{0} u_{c}\left(c_{1}, M_{1} / P_{1}\right) / \pi_{1}, \\
\left(R_{0}-1\right) u_{c}\left(c_{1}, M_{1} / P_{1}\right) / \pi_{1}=u_{a}\left(c_{0}, M_{0} / P_{0}\right) / \beta,
\end{gathered}
$$


and the transversality condition.

Remarkably, the two versions substantially differ with respect to the relevance of the price level. In the $E$-version the $P F E$ is purely forward-looking, such that consumption in the first period depends only on the fraction of the current values for the absolute price level and nominal money (see (20)). Thus, the absolute value for $P_{0}$ is irrelevant and the PFE is neutral with respect to $P_{0}$. In the $B$-version however, consumption $c_{0}$ relates to the fraction of the given initial value $M_{-1}$ and the price level $P_{0}$ (see (14)). Then, the price level is non-neutral for the PFE, such that a particular set of equilibrium sequences is associated with a unique price level sequence including a particular value for $P_{0}$. The following corollary states this substantial difference between the two versions.

Corollary 1 Given a set of equilibrium sequences $\left\{c_{t}, \pi_{t}\right\}_{t=0}^{\infty}$ and an initial value $M_{-1}$, the sequences of the absolute price level $\left\{P_{t}\right\}_{t=0}^{\infty}$ and nominal money $\left\{M_{t}\right\}_{t=0}^{\infty}$ are uniquely determined by (14) and (11) in the B-version, while in the E-version (20) and (17) define infinitely many pairs $P_{t}, M_{t}$ consistent with a perfect foresight equilibrium.

Notice that if consumption and real money balances enter the utility function separately, i.e. $u_{c a}=0$, the entire consumption path does not depend on the concrete values of the price level and nominal money - in both versions. Thus, the dependence of an allocation on the price level builds on the existence of real balance effects and on the assumption, that beginning-of-period money yields transaction services. To be more precise, if $u_{c a} \neq 0$, my assumptions about the utility function ensure, that the condition for the optimal intra-temporal substitution between leisure and consumption defines an implicit monotone function, $M_{t-1} / P_{t}=f\left(c_{t}\right)$ in the $B$-version (see (14) and (11)) and $m_{t}=f\left(c_{t}\right)$ in the $E$-version $\forall t \geq 0$, see (20) and (17). ${ }^{8}$ Thus, given $M_{-1}$, a specific

\footnotetext{
${ }^{8}$ The derivative for this implicit function, $f^{\prime}(\bullet)=-\left(u_{l l}+u_{c c}\right) / u_{c a}$, is monotone increasing for Edgeworth-Complements.
} 
value for consumption in the first period, is in the $B$-version associated with a unique value for the price level, $P_{0}$, while in the $E$-version, consumption relates only to a unique value of the fraction $M_{0} / P_{0}$.

The dependence of a given allocation on a particular initial absolute price level is often summarized by the notion "nominal determinacy" (see Benhabib et al., 2001a). It is crucial to note that the role of the price level in the first period does not relate to the unique determination of equilibrium sequences (including the inflation sequence) which is summarized by the notion "real determinacy". These properties are summarized in the following definition, which corresponds to the definition applied in Benhabib et al. (2001a).

Definition 2 The equilibrium displays real determinacy if there exists a unique set of equilibrium sequences $\left\{c_{t}, \pi_{t}, m_{t}, R_{t}\right\}_{t=0}^{\infty}$. Given $M_{-1}$, the equilibrium displays nominal indeterminacy if for any particular set of equilibrium sequences, there exist infinite many price levels $P_{0}$ consistent with a perfect foresight equilibrium.

Remarkably, for a set of equilibrium sequences to be characterized by nominal determinacy, it suffices, that one of the values $c_{0}, \pi_{0}, m_{0}$ or $R_{0}$ is associated with a particular price level in the first period $P_{0}$. If $u_{c a} \neq 0$ and the $B$-version applies, real determinacy (equilibrium uniqueness), is sufficient for the determination of $P_{0}$, such that nominal determinacy applies. However, in the $E$-version, the equilibrium displays nominal indeterminacy (see corollary 1) even if the equilibrium is characterized by real determinacy.

A PFE, which is characterized by real determinacy and, thus, a unique inflation sequence, can be associated with multiple price level sequences, even if beginning-ofperiod money enters the utility function. If, for example, there are no real balance effects $\left(u_{c a}=0\right)$, the price level is neutral with regard to the determination of equilibrium sequences $\left\{c_{t}, \pi_{t}, R_{t}\right\}_{t=0}^{\infty}$ under interest rate policy. Thus, two different values 
for the initial price level together with an equilibrium inflation sequence lead to two different price level sequences consistent with the PFE. Evidently, one cannot uniquely determine a unique price level sequence if there are infinitely many equilibrium inflation sequences. Independent of the existence of real balance effects, the $P F E$ under a constant money growth rule is associated with a unique price level sequence, whenever $\left\{m_{t}\right\}_{t=0}^{\infty}$ is uniquely determined.

To summarize, under interest rate policy and if there are no real balance effects, the equilibrium displays nominal indeterminacy in both versions. Given real determinacy and the presence of real balance effects, the equilibrium in the $B$-version exhibits nominal determinacy, while in the $E$-version the equilibrium is in any case associated with multiple price level sequences under interest rate policy. Whether real determinacy is ensured or not depends on monetary policy.

In the following analysis, I apply Blanchard and Kahn's (1980) approach to the analysis of a rational expectations equilibrium. For this, I focus on the model's behavior in the neighborhood of the steady state, and apply a linear approximation of the set of non-linear equilibrium conditions. Throughout, I restrict my attention to locally stable equilibrium sequences, i.e., to equilibrium sequences that converge to the steady state.

\subsection{Beginning-of-period money}

I start with the case where the beginning-of-period stock of money enters the utility function. The deterministic steady state is then characterized by the following properties: $\bar{R}=\bar{\pi} / \beta,-u_{l}(\bar{c})=u_{c}(\bar{c}, \bar{m} / \bar{\pi})$, and $u_{c}(\bar{c}, \bar{m} / \bar{\pi})(\bar{R}-1)=u_{a}(\bar{m} / \bar{\pi}, \bar{c}) . \mathrm{A}$ discussion of the existence and uniqueness of a steady state for $\bar{R}>1$ can be found in appendix 6.1 . Log-linearizing the model at the steady state, leads to the following set 
of equilibrium conditions:

$$
\begin{aligned}
\varepsilon_{c a} \widehat{m}_{t-1}-\varepsilon_{c a} \widehat{\pi}_{t} & =\left(\sigma_{l}+\sigma_{c}\right) \widehat{c}_{t}, \\
\sigma_{c} \widehat{c}_{t}-\varepsilon_{c a} \widehat{m}_{t-1}+\varepsilon_{c a} \widehat{\pi}_{t} & =\sigma_{c} \widehat{c}_{t+1}-\varepsilon_{c a} \widehat{m}_{t}+\left(\varepsilon_{c a}+1\right) \widehat{\pi}_{t+1}-\widehat{R}_{t}, \\
\left(\varepsilon_{c a}+\sigma_{a}\right) \widehat{m}_{t} & =-z \widehat{R}_{t}+\left(\sigma_{c}+\phi_{a c}\right) \widehat{c}_{t+1}+\left(\varepsilon_{c a}+\sigma_{a}\right) \widehat{\pi}_{t+1},
\end{aligned}
$$

where $z \equiv \bar{R} /(\bar{R}-1)>1, \sigma_{l} \equiv \frac{\overline{\bar{u}} \bar{u}_{l l}}{\bar{u}_{l}} \geq 0, \sigma_{c} \equiv-\frac{\overline{c u_{c c}}}{\bar{u}_{c}}>0, \sigma_{a} \equiv-\frac{\overline{a u}_{a a}}{\bar{u}_{a}}>0, \varepsilon_{c a} \equiv$ $\frac{\overline{a u}_{c a}}{\bar{u}_{c}}>0$, and $\phi_{a c} \equiv \frac{\overline{c u}_{a c}}{\bar{u}_{a}}>0$, and $\widehat{f}_{t}$ denotes the percent deviation of a generic variable $f_{t}$ from its steady state value $\bar{f}: \widehat{f}_{t}=\log \left(f_{t}\right)-\log (\bar{f})$. These conditions (and the transversality condition) have to be satisfied by the equilibrium sequences for the steady state deviations of consumption, real balances, the inflation rate, and of the nominal interest rate, $\left\{\widehat{c}_{t}, \widehat{\pi}_{t}, \widehat{m}_{t}, \widehat{R}_{t}\right\}_{t=0}^{\infty}$ and a monetary policy regime satisfying

$$
\widehat{R}_{t}=\rho_{\pi} \widehat{\pi}_{t}, \quad \text { or } \quad \widehat{R}_{t}=\rho_{\pi} \widehat{\pi}_{t+1}, \quad \text { or } \quad \widehat{m}_{t}=\widehat{m}_{t-1}-\widehat{\pi}_{t},
$$

where $\rho_{\pi}$ denotes the steady state inflation elasticity $\rho_{\pi} \equiv \rho^{\prime}(\bar{\pi})(\bar{\pi} / \bar{R}) \geq 0$. Following Benhabib et al. (2001), interest rate policy is called active or according to the Taylorprinciple if $\rho_{\pi}>1$, and passive if $\rho_{\pi}<1$. An active (passive) interest rate setting leads to an increase (decrease) in the real interest rate in response to an increase in the inflation measure. It should be noted that concavity of the utility function implies: $\Upsilon \equiv \sigma_{c} \sigma_{a}-\varepsilon_{c a} \phi_{a c}>0,{ }^{9}$ which restricts the magnitude of real balance effects. A closer look at the equilibrium conditions (23) and (24) reveals that the private sector behavior is not independent of the beginning-of-period value for real balances $\widehat{m}_{t-1}$, as they are (implicitly) assumed to lower households' transactions costs. Given that $\widehat{m}_{t-1}$ is predetermined, the households' behavior can induce the economy to evolve in a

\footnotetext{
${ }^{9} \mathrm{I}$ view this as a realistic implication, given that estimates of $\varepsilon_{c a}$ and $\phi_{a c}$, are usually found to be small. According to US estimates reported in Woodford (2003), $\varepsilon_{c a}$ does not exceed 0.005 and $\phi_{a c} \leq 2$.
} 
history dependent way, i.e. predetermined real money balances can be a state variable. Defining $\left[\widehat{m}_{t}, \widehat{c}_{t}, \widehat{\pi}_{t}, \widehat{R}_{t}\right]^{\prime} \equiv \widehat{x}_{t}$, the following definition summarizes this property.

Definition 3 Consider the fundamental solution for the equilibrium sequences $\left\{\widehat{x}_{t}\right\}_{t=0}^{\infty}$, that satisfies the equilibrium conditions (23)-(25) and one monetary policy rule (26). If there exists a locally stable and unique fundamental solution of the linear functional form

$$
\widehat{x}_{t}=\left(\begin{array}{c}
\eta_{m} \\
\eta_{c} \\
\eta_{\pi} \\
\eta_{R}
\end{array}\right) \widehat{m}_{t-1}=\Lambda \widehat{m}_{t-1} \quad \forall t \geq 0
$$

with $\eta_{i} \neq 0$ for $i=m, c, \pi, R$, then predetermined real money balances are an endogenous state variable.

It is crucial to note, that if real money balances are a state variable, then not only first period values $\widehat{x}_{0}$ are associated with a particular first period price level. Instead, the whole set of equilibrium variables is indexed with a specific value for $m_{-1}$ a at each point in time, i.e. $\widehat{x}_{t}=\Lambda{ }^{t+1} \widehat{m}_{-1}, \forall t>0$. For a given initial value $M_{-1}$, the set of equilibrium sequences relies on a particular initial price level $P_{-1}$. Since this mechanism applies to each period, the complete set of sequences for the absolute price level $\left\{P_{t}\right\}_{t=0}^{\infty}$ and nominal balances $\left.M_{t}\right\}_{t=0}^{\infty}$ is uniquely determined. Evidently, if real money balances are a state variable, the equilibrium displays nominal determinacy. But as will become clear below, the reverse must not be true.

Yet, $\widehat{m}_{t-1}$ enters the equilibrium conditions jointly with the current inflation rate. Thus, predetermined real money serves as a relevant endogenous state variable, only if the current inflation $\widehat{\pi}_{t}$ rate is uniquely determined, which implies real determinacy. Given real determinacy, nominal determinacy applies, whenever the beginning-of-period stock of money enters the utility function. But monetary policy is decisive for real de- 
terminacy, i.e. for the possibility to uniquely determine a price level sequence. In the subsequent analysis, I will show that this requires the central bank to set the nominal interest rate contingent on current inflation. Under an interest rate peg, $\rho_{\pi}=0$, an inflation sequence and, therefore, a price level sequence cannot be uniquely determined. ${ }^{10}$

I start with the case where the central bank sets the nominal interest rate according to an interest rate feedback rule. At first, I consider current inflation as the policy indicator, $\widehat{R}_{t}=\rho_{\pi} \widehat{\pi}_{t}$. The following proposition summarizes the equilibrium properties for the cases where the labor supply elasticity $1 / \sigma_{l}$ takes a finite value or is infinite.

Proposition 1 ( $B$, Interest rate policy, $\left.\widehat{R}_{t}=\rho_{\pi} \widehat{\pi}_{t}\right)$ Consider that beginning-of-period money enters the utility function and that the nominal interest rate is set contingent on changes in current inflation $\widehat{R}_{t}=\rho_{\pi} \widehat{\pi}_{t}$.

1. When the labor supply elasticity is finite, $\sigma_{l}>0$, predetermined real money balances serve as a state variable. The equilibrium displays real determinacy and local stability if and only if

(a) $\overline{\rho_{\pi 1}}<\rho_{\pi}<1$ for $\varepsilon_{c a}>\frac{\sigma_{a}}{2 z-1}$ and $\sigma_{l}>\overline{\sigma_{l}}$, leading to non-oscillatory equilibrium sequences, or $\rho_{\pi} \in\left(1, \overline{\rho_{\pi 1}}\right)$, leading to oscillatory equilibrium sequences,

(b) $\rho_{\pi}>1$ for $\varepsilon_{c a}<\frac{\sigma_{a}}{2 z-1}$ or $\sigma_{l}<\overline{\sigma_{l}}$, leading to oscillatory equilibrium sequences, where $\overline{\rho_{\pi 1}} \equiv \frac{\sigma_{l}\left(\varepsilon_{c a}+\sigma_{a}\right)+\Upsilon}{\sigma_{l}(2 z-1) \varepsilon_{c a}-\sigma_{l} \sigma_{a}-\Upsilon}$ and $\overline{\sigma_{l}} \equiv \frac{\Upsilon}{(2 z-1) \varepsilon_{c a}-\sigma_{a}}$.

2. When the labor supply elasticity is infinite, $\sigma_{l}=0$, predetermined real money balances do not serve as a state variable. Consumption $\widehat{c}_{t}$ cannot uniquely be determined, while the equilibrium sequences $\left\{\widehat{c}_{t+1}, \widehat{\pi}_{t}, \widehat{m}_{t}, \widehat{R}_{t}\right\}_{t=0}^{\infty}$ are locally stable and uniquely determined if and only if $\rho_{\pi}>1$.

\footnotetext{
${ }^{10}$ It should further be noted that a $P F E$ displays nominal indeterminacy if there are no real balance effects, $\varepsilon_{c a}=\phi_{a c}=0$. Nevertheless, one can always compute a price level sequence for a particular initial price level and a sequence of inflation rates.
} 
Proof. See appendix 6.2.

Proposition 1 reveals that the requirements for local equilibrium stability and uniqueness in terms of the policy parameter $\rho_{\pi}$ are not robust with regard to changes in the elasticities $\varepsilon_{c a}$ and $\sigma_{l} \cdot{ }^{11}$ For finite labor supply elasticities, $\sigma_{l}>0$, predetermined real balances serve as an endogenous state variable. Correspondingly, passiveness $\left(\rho_{\pi}<1\right)$ - a violation of the Taylor-principle - is necessary for locally stable, unique, and nonoscillatory equilibrium sequences (see part 1a). An interest rate peg, however, violates the conditions in part 1 of proposition 1 and, thus, implies real indeterminacy. On the contrary, if interest rate policy follows the Taylor-principle $\left(\rho_{\pi}>1\right)$, locally stable and unique equilibrium sequences are oscillatory, which is hardly recommendable for a central bank that aims at stabilizing the economy. Thus, when beginning-of-period money relates to households' consumption, interest rate policy that reacts on current inflation should rather be passive than active for macroeconomic stability and for the unique determination of the price level.

To see this, suppose that inflation exceeds its steady state value and equilibrium sequences are non-oscillatory. ${ }^{12}$ Given that the inflation elasticity is positive, $\rho_{\pi}>0$, the nominal interest rate rises, which - ceteris paribus - causes households to reduce their end-of-period real money holdings $\widehat{m}_{t}$, by (25). According to (24), the expected real interest rate is further negatively related to the growth rate of real balances. Thus, an active interest rate setting - implying an increase in the real interest rate - leads to a decline in the level and the growth rate of real balances, such that the sequences of real balances and, thus, of consumption and inflation do not converge to the steady state.

\footnotetext{
${ }^{11}$ Note that for the sets $\left(\overline{\rho_{\pi 1}}, 1\right)$ and $\left(1, \overline{\rho_{\pi 1}}\right)$ (see part 1a. of proposition 1) to be non-empty $\sigma_{l}>$ $\Upsilon\left[(z-1) \varepsilon_{c a}-\sigma_{a}\right]^{-1}$ and $\varepsilon_{c a}>\sigma_{a} /(z-1)$, and, respectively, $\sigma_{l}<\Upsilon\left[(z-1) \varepsilon_{c a}-\sigma_{a}\right]^{-1}$ or $\varepsilon_{c a}<\sigma_{a} /(z-1)$ has to be satisfied.

${ }^{12}$ The latter property implies that current and expected future inflation are not negatively related.
} 
Notably, the equilibrium exhibits different properties if the marginal disutility of labor is constant, i.e. if the inverse of the labor supply elasticity is zero (see part 2 of proposition 1). Then, the amount of labor supplied by the households is not related to their consumption expenditures and and the marginal utility of consumption is always identical to its steady state value (see 23). In this case, the Euler equation and money demand reduce to a constant real interest rate $\widehat{R}_{t}-\widehat{\pi}_{t+1}=0$, and $\sigma_{a} \widehat{m}_{t}=$ $-z \widehat{R}_{t}+\phi_{a c} \widehat{c}_{t+1}+\sigma_{a} \widehat{\pi}_{t+1}$, such that the equilibrium is not associated with a unique value for beginning-of-period real money and that current consumption $\widehat{c}_{t}$ cannot be determined. Correspondingly, predetermined real money balances do not serve as a state variable. The equilibrium sequences for $\widehat{c}_{t+1}, \widehat{\pi}_{t}, \widehat{m}_{t}$, and $\widehat{R}_{t}$ are then locally stable and uniquely determined for an active interest rate policy, which contrasts the results for the case of finite labor supply elasticities, $\sigma_{l}>0$, presented in part 1 of proposition 1.

I now turn to the case where the central bank applies a forward looking rule, $\widehat{R}_{t}=$ $\rho_{\pi} \widehat{\pi}_{t+1}$

Proposition $2\left(B\right.$, Interest rate policy, $\left.\widehat{R}_{t}=\rho_{\pi} \widehat{\pi}_{t+1}\right)$ Consider that beginning-ofperiod money enters the utility function and that the nominal interest rate is set contingent on changes in future inflation $\widehat{R}_{t}=\rho_{\pi} \widehat{\pi}_{t+1}$. Then, consumption and inflation cannot uniquely be determined and predetermined real money balances do not serve as a state variable.

1. When the labor supply elasticity is finite, $\sigma_{l}>0$, then $\rho_{\pi}>1$ is a necessary condition for uniqueness and local stability of the equilibrium sequences $\left\{\widehat{c}_{t+1}, \widehat{\pi}_{t+1}, \widehat{m}_{t}, \widehat{R}_{t}\right\}_{t=0}^{\infty}$. Necessary and sufficient conditions are given by:

(a) $1<\rho_{\pi}$ for $\sigma_{l}>\overline{\sigma_{l 2}}$ and $\varepsilon_{c a}>\frac{\sigma_{a}}{z-1}$, 
(b) $1<\rho_{\pi}<\overline{\rho_{\pi 2}}$, for $\sigma_{l}<\overline{\sigma_{l 2}}$ or $\varepsilon_{c a}<\frac{\sigma_{a}}{z-1}$, or $1<\overline{\rho_{\pi 2}}<\rho_{\pi}$ if $\sigma_{l}>\overline{\sigma_{l}}$ and $\varepsilon_{c a}>\frac{\sigma_{a}}{2 z-1}$, for $\sigma_{l} \in\left(\overline{\sigma_{l}}, \overline{\sigma_{l 2}}\right)$ or $\varepsilon_{c a} \in\left(\frac{\sigma_{a}}{2 z-1}, \frac{\sigma_{a}}{z-1}\right)$,

(c) $1<\overline{\rho_{\pi 2}}<\rho_{\pi}<-\overline{\rho_{\pi 1}}$ for $\sigma_{l}<\overline{\sigma_{l}}$ or $\varepsilon_{c a}<\frac{\sigma_{a}}{2 z-1}$,

where $\overline{\sigma_{l 2}} \equiv \frac{\Upsilon}{(z-1) \varepsilon_{c a}-\sigma_{a}}$ and $\overline{\rho_{\pi 2}} \equiv \frac{\Upsilon+\sigma_{l}\left(\varepsilon_{c a}+\sigma_{a}\right)}{\Upsilon+\sigma_{l}\left(\varepsilon_{c a}+\sigma_{a}\right)-z \varepsilon_{c a} \sigma_{l}}$.

2. When the labor supply elasticity is infinite, $\sigma_{l}=0$, then the equilibrium sequences $\left\{\widehat{c}_{t+1}, E_{t} \widehat{\pi}_{t+1}, \widehat{m}_{t}, \widehat{R}_{t}\right\}_{t=0}^{\infty}$ are locally stable and uniquely determined if and only if $\rho_{\pi} \neq 1$.

Proof. See appendix 6.3 .

In comparison to proposition 1 the most fundamental difference relates to the role of beginning-of-period real balances, $\widehat{m}_{t-1}$. If monetary policy applies a forward looking interest rate rule, households' optimal consumption decisions are not affected by predetermined real money balances. I.e. real money balances are not a state variable of the economy. The initial stock of real money balances $m_{-1}=M_{-1} / P_{-1}$ is irrelevant for the equilibrium allocation and thus, there are multiple price level sequences. Correspondingly, current inflation can not be pinned down since it enters jointly with $\widehat{m}_{t-1}$ and the equilibrium is consistent with infinitely many values for current inflation. Given that the current values for inflation and consumption can not be determined, households adjust $\widehat{m}_{t}$ in accordance with their planned future consumption $\widehat{c}_{t+1}$, implying that their behavior is not history dependent. On the contrary, if current inflation serves as a policy indicator, predetermined real money balances restrict households' consumption decisions and initial real money balances are relevant for the equilibrium sequences $\widehat{c}_{t}, \widehat{\pi}_{t}, \widehat{m}_{t}, \widehat{R}_{t}$ at each point in time: predetermined real money balances are an endogenous state variable (see definition 3) and the perfect foresight equilibrium is characterized by nominal determinacy. Remarkably in that case, by applying an 
interest rate rule, the complete set of nominal sequences, the absolute price level and nominal balances, can be uniquely determined.

Under an interest rate rule featuring current inflation, it turns out that there is no robust value for the inflation elasticity that ensures local stability and uniqueness. For example, when the real balance effect and the labor supply elasticity satisfy $\varepsilon_{c a}>\frac{\sigma_{a}}{2 z-1}$ and $\sigma_{l}>\frac{\Upsilon}{(2 z-1) \varepsilon_{c a}-\sigma_{a}}$, interest rate policy should be passive, $\rho_{\pi}<1$, while the inverse, $\rho_{\pi}>1$, is required under $\varepsilon_{c a}<\frac{\sigma_{a}}{2 z-1}$ or $\sigma_{l}<\overline{\sigma_{l}}$ (see proposition 1 ). When the central bank sets the nominal interest rate contingent on expected future inflation, activeness $\rho_{\pi}>1$ is always necessary (but not sufficient) for uniqueness. ${ }^{13}$ As in the previous case (see part 2 of proposition 1), the equilibrium exhibits different properties if the labor supply elasticity is infinite $\sigma_{l}=0$ as described in part 2 of proposition 2 . With a forward looking interest rate rule, the model then reduces to a set of static equilibrium conditions characterized by unique equilibrium sequences $\left\{\widehat{c}_{t+1}, \widehat{\pi}_{t+1}, \widehat{m}_{t}, \widehat{R}_{t}\right\}_{t=0}^{\infty}$ for any non-zero inflation elasticity $\rho_{\pi} \neq 1$.

Under a money growth regime equilibrium determination is less sensitive. Ruling out unreasonable parameter values, I focus, for convenience, on the case where the inverse of the elasticity of intertemporal substitution of money is not extremely large, $\sigma_{a}<z=\bar{R} /(\bar{R}-1){ }^{14}$

Proposition 3 ( $B$, Money growth policy) Suppose that beginning-of-period money enters the utility function and that $\sigma_{a}<z$. Under a constant money growth rule, predetermined real money balances do not serve as a state variable. The equilibrium sequences $\left\{\widehat{c}_{t+1}, \widehat{\pi}_{t+1}, \widehat{m}_{t}, \widehat{R}_{t}\right\} \forall t \geq 0$ are locally stable and uniquely determined, and there exists a unique consistent price level $\forall t \geq 0$.

\footnotetext{
${ }^{13}$ Non-emptiness of the sets for $\rho_{\pi}$ requires $\overline{\rho_{\pi 2}}>1$ and $-\overline{\rho_{\pi 1}}>\overline{\rho_{\pi 2}}$, which is fulfilled for the given restrictions on $\sigma_{l}$ and $\varepsilon_{c a}$ in part $1 \mathrm{~b}$ and $1 \mathrm{c}$.

${ }^{14}$ It should be noted that $\sigma_{a}<z$ is just a sufficient precondition for the result in proposition 3 and hardly restrictive if one assigns values for $\sigma_{a}$ that relate to reasonable magnitudes of $\sigma_{c}$.
} 
Proof. See appendix 6.4.

A comparison of the results in the propositions 1-3 shows that the PFE displays real determinacy, if and only if predetermined real money balances are an endogenous state variable. This requires an interest policy contingent on current inflation. Remarkably, the money growth regime leads to an equilibrium behavior being different from the behavior under both interest rate policy regimes. On the one hand, the price level can always be determined if real balances are determined, given that the value for the nominal stock of money is known in every period. On the other hand, the initial values for the inflation rate $\widehat{\pi}_{0}$ and real money $\widehat{m}_{-1}$ are irrelevant for equilibrium determination, implying that there are - for different initial price levels - multiple values for both which are consistent with a unique set of equilibrium sequences $\left\{\widehat{c}_{t+1}, \widehat{\pi}_{t+1}, \widehat{m}_{t}, \widehat{R}_{t}\right\}_{t=0}^{\infty}$. I.e. the equilibrium displays nominal determinacy but does not rely on predetermined real money balances as an endogenous state variable. Put differently, for the economy to evolve in a history dependent way, it is, therefore, not sufficient that monetary policy is conducted in a backward looking way. Instead, it is the households' consumption decision rather than a restriction on the evolution of money, which is responsible for the equilibrium sequences to depend on beginning-of-period money holdings. There is an analogy to the role of physical capital in a standard real business cycle model with a depreciation rate equal to one. Capital remains a relevant state variable, even though the model (virtually) lacks an accumulation equation. ${ }^{15}$

\footnotetext{
${ }^{15}$ Consider a real version of my model, with perfect competition, a production technology satisfying $y_{t}=s_{t} k_{t-1}^{\alpha} l_{t}^{1-\alpha}$, where $k_{t-1}$ denotes the beginning-of-period stock of physical capital and $\alpha \in(0,1)$, and a capital depreciation rate of $100 \%$. Nevertheless, capital serves as a relevant state variable, i.e., $k_{t-1}$ affects the equilibrium allocation in period $t$.
} 


\subsection{End-of-period money}

Next, I will briefly summarize the requirements for equilibrium determination under the assumption that end-of-period money holdings enter the utility function. In this case, the equilibrium displays nominal indeterminacy - unless monetary policy follows a constant money growth rule. This specification has also been examined by Benhabib et al. (2001a) and by Woodford (2003) for interest rate policies, and by Carlstrom and Fuerst (2003) for money growth rules. The deterministic steady state for this version is characterized by the following conditions, $\bar{R}=\bar{\pi} / \beta,-u_{l}(\bar{c})=u_{c}(\bar{c}, \bar{m})$, and $u_{c}(\bar{c}, \bar{m})(R-1)=u_{a}(\bar{m}, \bar{c}) \cdot{ }^{16}$ Log-linearizing the model summarized in definition 1 for $A_{t}=M_{t}$ at the steady state with $\bar{R}>1$ leads to the following set of equilibrium conditions:

$$
\begin{aligned}
\varepsilon_{c a} \widehat{m}_{t} & =\left(\sigma_{l}+\sigma_{c}\right) \widehat{c}_{t}, \\
\sigma_{c} \widehat{c}_{t}-\varepsilon_{c a} \widehat{m}_{t} & =\sigma_{c} \widehat{c}_{t+1}-\varepsilon_{c a} \widehat{m}_{t+1}-\widehat{R}_{t}+\widehat{\pi}_{t+1}, \\
\left(\varepsilon_{c a}+\sigma_{a}\right) \widehat{m}_{t} & =\left(\phi_{a c}+\sigma_{c}\right) \widehat{c}_{t}-(z-1) \widehat{R}_{t} .
\end{aligned}
$$

The conditions (28)-(30), the transversality condition, and a monetary policy rule (26) have to be satisfied by the equilibrium sequences $\left\{\widehat{c}_{t}, \widehat{\pi}_{t}, \widehat{m}_{t}, \widehat{R}_{t}\right\}_{t=0}^{\infty}$. In contrast to the $B$-version, consumption and inflation are independent of beginning-of-period real balances. To put it differently, predetermined real money balances can not serve as a state variable. Instead, the private sector behavior is entirely forward-looking in the $E$-version with the consequence that the equilibrium displays nominal indeterminacy under interest rate policy.

The following proposition summarizes the conditions for equilibrium determination under interest rate policy.

\footnotetext{
${ }^{16} \mathrm{~A}$ discussion of steady state uniqueness is provided in appendix 6.1 .
} 
Proposition 4 (E, Interest rate policy) Suppose that end-of-period money enters the utility function and that the central bank sets the nominal interest rate.

1. When current inflation enters the interest rate rule, $\widehat{R_{t}}=\rho_{\pi} \widehat{\pi_{t}}$, the equilibrium displays real determinacy and local stability if and only if $\rho_{\pi}>1$.

2. When future inflation enters the interest rate rule, $\widehat{R_{t}}=\rho_{\pi} \widehat{\pi}_{t+1}$, inflation cannot uniquely be determined. The equilibrium sequences $\left\{\widehat{c}_{t}, \widehat{\pi}_{t+1}, \widehat{m}_{t}, \widehat{R}_{t}\right\}_{t=0}^{\infty}$ are locally stable and uniquely determined if and only if i) $\rho_{\pi}>1$ or $\rho_{\pi}<\left(1+\frac{2(z-1) \sigma_{l} \varepsilon_{c a}}{\Upsilon+\sigma_{l}\left(\varepsilon_{c a}+\sigma_{a}\right)}\right)^{-1}$ for $\sigma_{l}>0$, and ii) $\rho_{\pi} \neq 1$ for $\sigma_{l}=0$.

Proof. See appendix 6.5.

As in the $B$-version, equilibrium determination depends on the particular interest rate rule. When the nominal interest rate is set contingent on current inflation, inflation can be determined for all periods. Under a forward looking interest rate policy, one can only uniquely determine future inflation. In any case, the initial price level and initial real balances are irrelevant for a $R E E$, implying nominal indeterminacy and the absence of an endogenous state variable. Uniqueness of equilibrium sequences is further ensured by an active interest rate policy, $\rho_{\pi}>1$, under both types of rules. For the special case, where the labor supply elasticity is infinite, any forward looking interest rate rule satisfying $\rho_{\pi} \neq 1$ leads to unique equilibrium sequences $\left\{\widehat{c}_{t}, \widehat{\pi}_{t+1}, \widehat{m}_{t}, \widehat{R}_{t}\right\}_{t=0}^{\infty}$. Turning to the case where the central bank holds the money growth rate constant, I find that the equilibrium behavior closely relates to the one in the $B$-version.

Proposition 5 (E, Money growth policy) Suppose that end-of-period money enters the utility function and that the money growth rate is held constant. Then, the equilibrium sequences $\left\{\widehat{c}_{t}, \widehat{m}_{t}, \widehat{R}_{t}\right\} \forall t \geq 0$ and $\left\{\widehat{\pi}_{t}\right\} \forall t \geq 1$ are locally stable and uniquely determined, and there exists a unique consistent price level $\forall t \geq 0$. 
Proof. See appendix 6.6.

To summarize, the specification of money demand has substantial consequences for the determination of equilibrium sequences and for macroeconomic stability. The beginning-of-period value for real money balances is only relevant for equilibrium determination in the $B$-version under a non-forward looking interest rate rule. In the $E$-version, where the households' behavior lacks any backward looking element, the initial value of real balances is irrelevant for any policy regime under consideration. Whether beginning-of period real money is serving as a relevant endogenous state variable or not, is, on the one hand, decisive for a unique determination of the price level, and, on the other hand, crucially affects the conditions for local stability and uniqueness under an interest rate policy regime: policy should rather be passive than active, to avoid unstable or oscillatory equilibrium sequences. Under a constant money growth regime, however, local stability and uniqueness of equilibrium sequences and a unique price level sequence is ensured for both versions - regardless of the labor supply elasticity. Given that the stock of money is known in every period, a unique sequence for real money balances suffices to pin down uniquely the entire sequence for the absolute price level. Evidently, this does not require the economy to evolve in a history dependent way.

\subsection{Related results}

The main novel results in this section refer to the case where beginning-of-period money enters the utility function and the central bank applies an interest rate rule, while some results for the alternative cases correspond to results in related studies on real balances effects and equilibrium determinacy in flexible price models. For example, my findings for the $E$-version (see part 1 of proposition 4) resemble the results in Benhabib et al. 
(2001a) and Woodford (2003) for non-separable utility functions. They find that when current inflation serves as an indicator, active interest rate setting is necessary and sufficient for local stability and uniqueness. This, however, changes when beginning-ofperiod money provides utility, since equilibrium sequences are then - except for the case $\sigma_{l}=0$ - unstable or oscillatory (see proposition 1 ). Thus, the literature has disregarded the role of predetermined real balances as a relevant state variable, which substantially affects the real and nominal determinacy properties.

If the monetary authority applies a constant money growth rule, then local stability and uniqueness impose restrictions on preferences only in case where the stock of money held at the beginning of the period provides utility. In particular, the inverse of the intertemporal elasticity of substitution for real money balances should not be too large (see proposition 3), which corresponds to the results in Brock (1974), Matsuyama (1990), Carlstrom and Fuerst (2003), and Woodford (2003). Assuming that end-of-period money provides transaction services, Brock (1974), Matsuyama (1990), and Woodford (2003), show that local stability and uniqueness is ensured if consumption and real balances are Edgeworth-complements, as in my framework. Furthermore, Carlstrom and Fuerst (2003) find that the intertemporal elasticity of substitution for money can matter for local stability and uniqueness is guaranteed, as in proposition 3.

To unveil the role of non-separability for the results and to facilitate comparisons with related studies (see, e.g., Carlstrom and Fuerst, 2001), I further briefly discuss the case where money demand is separable, $\varepsilon_{c a}=\phi_{a c}=0$. Then, the model reduces to

$$
\widehat{R}_{t}=E_{t} \widehat{\pi}_{t+1}, \text { and } \sigma_{a} \widehat{m}_{t}=\left\{\begin{array}{cc}
-\left(z-\sigma_{a}\right) \widehat{R}_{t} & \text { for the } B \text {-version } \\
-(z-1) \widehat{R}_{t} & \text { for the } E \text {-version }
\end{array}\right.
$$

while consumption is exogenously determined. When utility is separable, the conditions for uniqueness under money growth policy, which are presented in proposition 3 and 5 , 
are unchanged. In contrast to the results for the non-separable case, the particular stock of money that enters the utility function is now irrelevant for equilibrium determination under interest rate policy: Equilibrium uniqueness requires $\rho_{\pi}>1$ for $\widehat{R}_{t}=\rho_{\pi} \widehat{\pi}_{t}$ and $\rho_{\pi} \neq 1$ for $\widehat{R}_{t}=\rho_{\pi} \widehat{\pi}_{t+1}$, which accords to the results in Carlstrom and Fuerst (2001). As in the case of non-separable utility, current inflation cannot be determined under a forward looking interest rate rule, while under a money growth rule inflation is only indetermined in the first period.

\section{Imperfectly Flexible Prices}

In a framework with monopolistic competitive firms and staggered price setting as developed by Calvo (1983), the initial price level belongs to the set of relevant state variables. ${ }^{17}$ Under this specification, real balances serve as a relevant predetermined state variable for all aforementioned policy rules, when the beginning-of-period specification applies. If, however, the end-of-period stock of money enters the utility function, households are entirely forward looking, and real money serves as a relevant state variable only if monetary policy is history dependent, i.e., when the central bank applies a money growth rule. Nonetheless, the determinacy properties under constant money growth and sticky prices correspond to those under flexible prices. The main implications for equilibrium uniqueness and stability under imperfectly flexible prices are as follows:

- When beginning-of-period money provides utility, interest rate policy has to be passive to lead to locally stable, unique, and non-oscillatory equilibrium sequences, regardless whether current or future inflation enters the policy rule. An active

\footnotetext{
${ }^{17}$ Please refer to Schabert and Stoltenberg (2005) for details in that case.
} 
interest rate policy is associated with locally stable and unique equilibrium sequences if and only if end-of-period money provides utility and current inflation serves as the policy indicator. ${ }^{18}$

- As under flexible prices, the central bank can ensure equilibrium sequence to be uniquely determined, locally stable, and non-oscillatory under both timing specifications by holding the growth rate of money constant, provided that real balance effects are not extremely large.

\section{Conclusion}

Real balance effects typically arise when transaction costs are specified in a general equilibrium model in form of shopping time or real resource costs, which are reduced by money holdings. The fact that the equilibrium sequences for real balances and consumption can then not separately be determined, is broadly viewed as negligible for the assessment of monetary policy, given that empirical evidence suggests real balance effects to be relatively small (Ireland, 2004). In contrast to this view, it is demonstrated in this paper that the existence (not the magnitude) of real balance effects has substantial implications for the determination of a rational expectations equilibrium and of the price level under interest rate policy.

However, for real balance effects to contribute to price level determination, as for example suggested by Patinkin $(1949,1965)$, predetermined real money balances have to serve as a state variable. Remarkably, these properties require that the stock of money at the beginning of the period yields transaction services, which corresponds to Svensson's timing assumption (1985), that the goods market closes before the asset

\footnotetext{
${ }^{18}$ To be more precise, these results apply for finite labor supply elasticities. For the case of an infinite labor supply elasticity there is a related paper by Brckner and Schabert, 2005. Assuming staggered price setting and a specific functional form for utility, they consider the implications of the timing of markets on optimal monetary policy under discretion.
} 
market opens. Hence, real money that has been acquired in the previous period restricts households' current consumption expenditures. Then, there exists a unique initial price level that is consistent with a rational expectations equilibrium, i.e., the equilibrium displays nominal determinacy. In that case, interest policy should be passive to ensure unique, non-oscillatory and locally stable equilibrium sequences - a violation of the Taylor-principle. If, on the other hand, current consumption is related to the end-ofperiod stock of money, then the equilibrium displays nominal indeterminacy, and the well-known principles for uniqueness and stability of equilibrium sequences of a cashless economy (roughly) apply. Remarkably, these results highlight, that the existence and timing of real balance effects jointly have substantial implications for equilibrium determination.

If monetary policy follows a constant money growth rule, the conditions for equilibrium uniqueness are likely to be ensured. Though the economy does not evolve in a history dependent way, the entire path for the absolute price level is uniquely determined in both versions. These results suggest that a central bank that aims to avoid multiple, unstable, or oscillatory equilibrium sequences in an environment where transaction frictions are non-negligible, should rather control the supply of money than the nominal interest rate.

Yet, an optimal conduct of monetary policy will certainly require the supply of money to be state contingent (as an interest rate feedback rule), which might be associated with different determinacy implications than a constant money growth regime. 


\section{Appendix}

\subsection{Existence and uniqueness of the steady state}

In this appendix, I briefly examine the steady state properties of the model. I restrict my attention to the case where the nominal interest rate is strictly positive, $R-1>0$. I further omit, for convenience, bars which are throughout the paper used to mark steady state values.

When the stock of money at the beginning of the period enters the utility function, the deterministic steady state is characterized by the following conditions: $-u_{l}(c)=$ $u_{c}(c, m / \pi)(\epsilon-1) / \epsilon, R=\pi / \beta$ and $u_{a}(c, m / \pi)\left(u_{c}(c, m / \pi)\right)^{-1}=R-1$. For an interest rate policy regime, it is assumed that the policy rule of the central bank, $R(\pi)$, has a unique solution for the steady state relation $R=\pi / \beta$, so that the inflation rate can be substituted out. The first equation implies that $c$ is an implicit function of $m, c=f(m)$, with $f^{\prime}(m)=-u_{c a}(\epsilon-1)\left[R \beta \epsilon\left(u_{l l}+u_{c c}(\epsilon-1) / \epsilon\right)\right]^{-1}>0$. Using this, the third equation can be used to determine the steady state value for $m$ with $u_{a}(f(m), m / \pi)\left[u_{c}(f(m), m /(R \beta))\right]^{-1}=R-1$. Differentiating the fraction on the left hand side reveals that

$$
\frac{d u_{a} / u_{c}}{d m}=\frac{u_{c}(\epsilon-1) / \epsilon\left(u_{c c} u_{a a}-u_{c a}^{2}\right)+u_{l l}\left(u_{a a} u_{c}-u_{a} u_{c a}\right)}{R \beta u_{c}^{2}\left(u_{l l}+u_{c c}(\epsilon-1) / \epsilon\right)}<0,
$$

as I assumed concavity for $u(c, a)$. It follows that a globally unique steady state exists if and only if:

$$
\lim _{m \rightarrow 0} \frac{u_{a}(f(m), m / R \beta)}{u_{c}(f(m), m /(R \beta))}>R-1 .
$$

Thus, steady state uniqueness relies on money to be essential (see Obstfeld and Rogoff, 1983): The marginal utility of real money balances should grow with a rate that is higher than the rate by which $1 / u_{c}$ converges to zero when $m$ approaches 
zero. An analogous line of arguments in case of a money growth policy leads to the condition $\lim _{m \rightarrow 0} u_{a}(g(m), m / \mu)\left[u_{c}(g(m), m / \mu)\right]^{-1}>\mu / \beta-1$, where $c=g(m)$ is the implicit relation derived of the steady state condition $-u_{l}(c)=u_{c}(c, m / \mu)$ with $g^{\prime}(m)=-u_{c a}(\epsilon-1)\left[\mu \epsilon\left(u_{l l}+u_{c c}(\epsilon-1) / \epsilon\right)\right]^{-1}>0$. The condition for existence and uniqueness for the interest rate policy regime if end-of-period money provides transaction services is

$$
\lim _{m \rightarrow 0} \frac{u_{a}\left(f_{E}(m), m\right)}{u_{c}\left(f_{E}(m), m\right)}>\frac{R-1}{R}
$$

with $f_{E}(m)^{\prime}=-u_{c a}(\epsilon-1)\left[\epsilon\left(u_{l l}+u_{c c}(\epsilon-1) / \epsilon\right)\right]^{-1}>0$. If the monetary authority applies a constant money growth rule then $\lim _{m \rightarrow 0} u_{a}\left(f_{E}(m), m\right)\left[u_{c}\left(f_{E}(m), m\right)\right]^{-1}>$ $(\mu / \beta-1) /(\mu / \beta)$ must be satisfied.

\subsection{Proof of proposition 1}

Consider a monetary policy regime that sets the nominal interest rate contingent on changes in current inflation, $\widehat{R}_{t}=\rho_{\pi} \widehat{\pi}_{t}$.

First, I establish the conditions for local stability and uniqueness. Second, if the labor supply supply elasticity is finite, I show that the existence of exactly one stable eigenvalue (assigned to real money balances, $\eta_{m}$ ) implies non-zero coefficients $\eta_{i}, i=$ $c, \pi, R$ of the fundamental solution.

Reducing the model in (23)-(25) leads to the following system in inflation and real money balances:

$$
\begin{aligned}
\left(\begin{array}{c}
\widehat{\pi}_{t+1} \\
\widehat{m}_{t}
\end{array}\right) & =\left(\begin{array}{cc}
\frac{\sigma_{l} \varepsilon_{c a}}{\sigma_{l}+\sigma_{c}}+1 & -\frac{\sigma_{l} \varepsilon_{c a}}{\sigma_{l}+\sigma_{c}} \\
\frac{\Upsilon+\sigma_{l}\left(\varepsilon_{c a}+\sigma_{a}\right)}{\sigma_{c}+\sigma_{l}} & -\frac{\Upsilon+\sigma_{l}\left(\varepsilon_{c a}+\sigma_{a}\right)}{\sigma_{c}+\sigma_{l}}
\end{array}\right)^{-1}\left(\begin{array}{cc}
\frac{\sigma_{l} \varepsilon_{c a}}{\sigma_{l}+\sigma_{c}}+\rho_{\pi} & -\frac{\sigma_{l} \varepsilon_{c a}}{\sigma_{l}+\sigma_{c}} \\
z \rho_{\pi} & 0
\end{array}\right)\left(\begin{array}{c}
\widehat{\pi}_{t} \\
\widehat{m}_{t-1}
\end{array}\right) \\
& =\mathbf{A}\left(\begin{array}{c}
\widehat{\pi}_{t} \\
\widehat{m}_{t-1}
\end{array}\right) .
\end{aligned}
$$


The characteristic polynomial of $A$ can be simplified to

$$
F(X)=X^{2}-X \rho_{\pi} \frac{\Upsilon+\sigma_{l}\left(\varepsilon_{c a}+\sigma_{a}\right)-z \sigma_{l} \varepsilon_{c a}}{\Upsilon+\sigma_{l}\left(\varepsilon_{c a}+\sigma_{a}\right)}-\frac{\rho_{\pi} z \sigma_{l} \varepsilon_{c a}}{\Upsilon+\sigma_{l}\left(\varepsilon_{c a}+\sigma_{a}\right)} .
$$

Consider the case the labor supply elasticity is finite $\sigma_{l}>0$. In this case, the determinant of $A, \operatorname{det}(A)=F(0)<0$, is strictly negative, indicating that exactly one eigenvalue is negative and that real money balances are a relevant state variable. Local stability and uniqueness then requires that there exists exactly one root of $F(X)=0$ with modulus less than one. To examine the conditions for this, I use that $F(X)$ further satisfies

$$
\begin{aligned}
F(1) & =1-\rho_{\pi} \\
F(-1) & =\frac{\left(1+\rho_{\pi}\right)\left(\Upsilon+\sigma_{l}\left(\varepsilon_{c a}+\sigma_{a}\right)\right)-2 z \sigma_{l} \varepsilon_{c a} \rho_{\pi}}{\Upsilon+\sigma_{l}\left(\varepsilon_{c a}+\sigma_{a}\right)} .
\end{aligned}
$$

Thus, for $F(1)<0(>0)$ and $F(-1)>0(<0)$, the model is locally stable, unique and (non-)oscillatory, since the stable eigenvalue is negative (positive).

Thus, for $F(1)>0$ and $F(-1)<0$ ), the model is locally stable, unique and nonoscillatory, since the stable eigenvalue is positive. If $F(1)<0$ and $F(-1)>0$, equilibrium sequences are locally stable and unique, but oscillatory, since the stable eigenvalue has a negative sign. Suppose that the real balance effect and that the inverse of the labor supply elasticity are large enough such that $\varepsilon_{c a}>\sigma_{a}(2 z-1)^{-1}$ and $\sigma_{l}>\overline{\sigma_{l}}$, where $\overline{\sigma_{l}} \equiv \frac{\Upsilon}{(2 z-1) \varepsilon_{c a}-\sigma_{a}}$. Then, $F(-1)$ can be negative if $\rho_{\pi}$ is sufficiently large. Local stability and uniqueness with $F(1)>0$ and $F(-1)<0$, is then ensured by moderate inflation elasticities satisfying $\overline{\rho_{\pi 1}}<\rho_{\pi}<1$, where $\overline{\rho_{\pi 1}} \equiv \frac{\sigma_{l}\left(\varepsilon_{c a}+\sigma_{a}\right)+\Upsilon}{\sigma_{l}(2 z-1) \varepsilon_{c a}-\sigma_{l} \sigma_{a}-\Upsilon}$. Alternatively, local stability and uniqueness arise for $F(1)<0$ and $F(-1)>0$, which requires $1<\rho_{\pi}<\overline{\rho_{\pi 1}}$. Suppose that $\varepsilon_{c a}>\sigma_{a}(2 z-1)^{-1}$ or $\sigma_{l}<\overline{\sigma_{l}}$. Then, $F(-1)$ cannot be negative and local stability and uniqueness then arise if $\rho_{\pi}>1$. 
To establish the role of predetermined real money balances as a state variable, I need to show that the coefficients $\eta_{i}, i=c, \pi, R$ are non-zero if $\eta_{m}$ is non-zero and stable. Applying the method of undetermined coefficients to (23) results in the following restrictions for the coefficients $\eta_{c}$ and $\eta_{\pi}$ :

$$
\eta_{c}=\frac{\varepsilon_{c a}\left(1-\eta_{\pi}\right)}{\sigma_{+} \sigma_{l}}
$$

implying that for $\varepsilon>0$ one not both coefficients can be zero. In particular, if $\eta_{\pi}$ is neither zero nor 1, predetermined real money balances are a relevant endogenous state variable for $\rho_{\pi} \neq 0$. The money demand equation (25) implies that

$$
\eta_{\pi}=-\frac{\eta_{m} k}{z \rho_{\pi}-\eta_{m} k} \neq 0,1
$$

since $k=\Upsilon+\sigma_{l}\left(\sigma_{c}+\sigma_{a}\right)>0$ due to strict concavity and $\rho_{\pi} \neq 0$ (no interest rate peg).

Now, consider the case where the labor supply elasticity is infinite, $\sigma_{l}=0$. In this case $\operatorname{det}(A)=0$, indicating that the beginning-of-period value for real money balances is irrelevant for the determination of $\widehat{\pi}_{t}$ and $\widehat{m}_{t}$. It follows that one eigenvalue equals zero and the other eigenvalue is larger than one, if and only if $\rho_{\pi}>1$. Then, the equilibrium sequences for $\widehat{m}_{t}, \widehat{c}_{t+1}, \widehat{\pi}_{t}$ and $\widehat{R_{t}}$ for $t \geq 0$ are locally stable and uniquely determined, while $\widehat{c}_{t}$ cannot be determined.

\subsection{Proof of proposition 2}

Consider a monetary regime in which future inflation serves as the policy indicator, $\widehat{R}_{t}=\rho_{\pi} E_{t} \widehat{\pi}_{t+1}$. Substituting for consumption with (23) and inserting the forward- 
looking feedback rule, the model in (23)-(25) can be reduced to

$$
\begin{aligned}
\left(\begin{array}{c}
\widehat{\pi}_{t+1} \\
\widehat{m}_{t}
\end{array}\right) & =\left(\begin{array}{cc}
\frac{\sigma_{l} \varepsilon_{c a}}{\sigma_{l}+\sigma_{c}}+1-\rho_{\pi} & -\frac{\sigma_{l} \varepsilon_{c a}}{\sigma_{l}+\sigma_{c}} \\
\frac{\Upsilon+\sigma_{l}\left(\varepsilon_{c a}+\sigma_{a}\right)}{\sigma_{c}+\sigma_{l}}-z \rho_{\pi} & -\frac{\Upsilon+\sigma_{l}\left(\varepsilon_{c a}+\sigma_{a}\right)}{\sigma_{c}+\sigma_{l}}
\end{array}\right)^{-1}\left(\begin{array}{cc}
\frac{\sigma_{l} \varepsilon_{c a}}{\sigma_{l}+\sigma_{c}} & -\frac{\sigma_{l} \varepsilon_{c a}}{\sigma_{l}+\sigma_{c}} \\
0 & 0
\end{array}\right)\left(\begin{array}{c}
\widehat{\pi}_{t} \\
\widehat{m}_{t-1}
\end{array}\right) \\
& =\mathbf{B}\left(\begin{array}{c}
\widehat{\pi}_{t} \\
\widehat{m}_{t-1}
\end{array}\right) .
\end{aligned}
$$

The characteristic polynomial of $\mathbf{B}$ is given by

$$
F(X)=X\left(X-\frac{\rho_{\pi} z \sigma_{l} \varepsilon_{c a}}{\left(\Upsilon+\sigma_{l}\left(\varepsilon_{c a}+\sigma_{a}\right)\right)\left(1-\rho_{\pi}\right)+\rho_{\pi} z \sigma_{l} \varepsilon_{c a}}\right) .
$$

Evidently, real money balances are not a relevant state variable, and one can only solve for $\widehat{m}_{t}, E_{t} \widehat{\pi}_{t+1}, E_{t} \widehat{c}_{t+1}$ and $\widehat{R}_{t} \forall t \geq 0$. For a finite labor supply elasticity, $\sigma_{l}>0$, local stability and uniqueness requires the other eigenvalue (one is equal to zero) to be unstable. A positive unstable root arises if monetary policy is active and $\sigma_{l}>\overline{\sigma_{l 2}}$ or if $1<\rho_{\pi}<\overline{\rho_{\pi 2}}$ for $\sigma_{l}<\overline{\sigma_{l 2}}$ or $\varepsilon_{c a}<\sigma_{a} /(2 z-1)$. A negative unstable root exists if $\rho_{\pi}>\overline{\rho_{\pi 2}}$, given that $\sigma_{l}>\overline{\sigma_{l}}$ and $\varepsilon_{c a}>\sigma_{a} /(2 z-1)$, for $\sigma_{l}<\overline{\sigma_{l 2}}$ or $\varepsilon_{c a}<\sigma_{a} /(2 z-1)$. Thus, $1<\overline{\rho_{\pi 2}}<\rho_{\pi}<-\overline{\rho_{\pi 1}}$ leads to a locally stable and unique equilibrium with a

negative root for $\sigma_{l}<\overline{\sigma_{l}}$ or $\varepsilon_{c a}<\sigma_{a} /(2 z-1)$. When the labor supply elasticity is infinite, $\sigma_{l}=0$, then the Euler equation reads $\left(1-\rho_{\pi}\right) \widehat{\pi}_{t+1}=0$. Thus, the model displays local stability and uniqueness if and only if $\rho_{\pi} \neq 1$.

\subsection{Proof of proposition 3}

Under a constant money growth regime the nominal interest rate can be substituted out so that the reduced form system of the model in (23)-(25) reads (where I omitted 
the exogenous state)

$$
\begin{aligned}
\varpi_{1} \widehat{c}_{t+1}-\left(\varpi_{2}+1\right) \widehat{m}_{t}+\varpi_{2} \widehat{\pi}_{t+1} & =-\sigma_{c} \widehat{c}_{t}+\varepsilon_{c a} \widehat{m}_{t-1}-\varepsilon_{c a} \widehat{\pi}_{t}, \\
\varepsilon_{c a} \widehat{m}_{t-1} & =\left(\sigma_{l}+\sigma_{c}\right) \widehat{c}_{t}+\varepsilon_{c a} \widehat{\pi}_{t},
\end{aligned}
$$

where $\varpi_{1} \equiv\left(\sigma_{c}(1-z)+\phi_{a c}\right) z^{-1}$ and $\varpi_{2} \equiv\left(\varepsilon_{c a}(1-z)-z+\sigma_{a}\right) z^{-1}$, and $\widehat{m}_{t}=\widehat{m}_{t-1}-$ $\widehat{\pi}_{t}$. After eliminating consumption with (32) and inflation with the linearized money growth rule (26), I get the following difference equation in $\widehat{m_{t}}$ :

$$
\widehat{m}_{t+1}=\frac{z\left(\sigma_{l} \varepsilon_{c a}+\sigma_{l}+\sigma_{c}\right)}{z\left(\sigma_{l} \varepsilon_{c a}+\sigma_{l}+\sigma_{c}\right)-\left(\Upsilon+\sigma_{l} \varepsilon_{c a}+\sigma_{l} \sigma_{a}\right)} \widehat{m}_{t} .
$$

Once $\widehat{m}_{t}$ is determined, which requires an unstable root, one can solve for $\widehat{\pi}_{t}$ and $\widehat{c}_{t} \forall t \geq$ 1 , while the initial values for consumption $\widehat{c}_{0}$ and inflation $\widehat{\pi}_{0}$ cannot be determined. Local uniqueness and stability of the equilibrium sequences $\left\{\widehat{m}_{t}, \widehat{\pi}_{t+1}, \widehat{c}_{t+1}, \widehat{R}_{t}\right\}_{t=0}^{\infty}$ thus require $\left|\frac{z\left(\sigma_{l} \varepsilon_{c a}+\sigma_{l}+\sigma_{c}\right)}{z\left(\sigma_{l} \varepsilon_{c a}+\sigma_{l}+\sigma_{c}\right)-\left(\Upsilon+\sigma_{l} \varepsilon_{c a}+\sigma_{l} \sigma_{a}\right)}\right|>1$. If $z\left(\sigma_{l} \varepsilon_{c a}+\sigma_{l}+\sigma_{c}\right)-\left(\Upsilon+\sigma_{l} \varepsilon_{c a}+\sigma_{l} \sigma_{a}\right)>0$, then the root is positive and unstable. Rearranging and using $\Upsilon=\sigma_{c} \sigma_{a}-\varepsilon_{c a} \phi_{a c}$ shows that this conditions is satisfied for $z>\sigma_{a}$.

\subsection{Proof of proposition 4}

Consider the case where the central bank sets the nominal interest rate contingent on changes in current inflation, $\widehat{R}_{t}=\rho_{\pi} \widehat{\pi}_{t}$. After substituting for consumption and eliminating $\widehat{m}_{t}$ and $\widehat{m}_{t+1}$ with the static money demand equation (30), one obtains the following difference equation (where I omitted the exogenous state):

$$
(d+1) \rho_{\pi} \widehat{\pi}_{t}=\left(d \rho_{\pi}+1\right) \widehat{\pi}_{t+1}
$$


where $d \equiv(z-1) \sigma_{l} \varepsilon_{c a}\left[\Upsilon+\sigma_{l}\left(\varepsilon_{c a}+\sigma_{a}\right)\right]^{-1}>0$. Therefore $\rho_{\pi}>1$ is necessary and sufficient for local stability and uniqueness of the equilibrium sequences of inflation $\widehat{\pi}_{t}$, real balances $\widehat{m_{t}}$, consumption $\widehat{c_{t}}$ and the nominal interest rate, $\widehat{R}_{t} \forall t \geq 0$.

Now, consider the case where future inflation serves as the policy indicator, $\widehat{R}_{t}=$ $\rho_{\pi} \widehat{\pi}_{t+1}$. When the labor supply elasticity is finite, $\sigma_{l}>0$, then the model in (28)-(30) reduces to:

$$
\widehat{\pi}_{t+2}=\frac{\rho_{\pi}(1+d)-1}{d \rho_{\pi}} \widehat{\pi}_{t+1}
$$

Evidently, one cannot determine current inflation rate $\widehat{\pi}_{t}$. One obtains a unique and locally stable solution for expected inflation, and the current values of consumption, real money balances and the nominal interest rate, if the eigenvalue of this equation is positive and unstable, which requires $\rho_{\pi}>1$. Alternatively, $\rho_{\pi}<[1+2 d]^{-1}$ ensures local stability and uniqueness, where one eigenvalue is smaller than -1 . When the labor supply elasticity is infinite, $\sigma_{l}=0$, then uniqueness of a equilibrium sequence for $\widehat{\pi}_{t+1} \forall t \geq 0$ is guaranteed by $\rho_{\pi} \neq 1$

\subsection{Proof of proposition 5}

Under a constant money growth policy, $\widehat{m}_{t}=\widehat{m}_{t-1}-\widehat{\pi}_{t}$, the model in (28)-(30) can by eliminating the nominal interest rate - be reduced to:

$$
\begin{aligned}
\varepsilon_{c a} \widehat{m}_{t} & =\left(\sigma_{l}+\sigma_{c}\right) \widehat{c}_{t} \\
\gamma_{1} \widehat{c}_{t+1}+\gamma_{2} \widehat{\pi}_{t+1}+\gamma_{3} \widehat{m}_{t} & =\left(\gamma_{1}+\frac{\sigma_{c}+\phi_{a c}}{z}\right) \widehat{c}_{t}
\end{aligned}
$$

where $\gamma_{1}=\sigma_{c}(z-1) z^{-1}>0, \gamma_{2}=\left(1+\varepsilon_{c a}\right)(z-1) z^{-1}>0$ and $\gamma_{3}=\left(\varepsilon_{c a}+\sigma_{a}\right) z^{-1}>0$. Eliminating consumption with (33) and inflation with the linearized money growth rule 
leads to the following difference equation in real money balances:

$$
\widehat{m}_{t+1}=\frac{\left[\sigma_{l}\left(1+\varepsilon_{c a}\right)+\sigma_{c}\right](z-1)+\Upsilon+\sigma_{l}\left(\varepsilon_{c a}+\sigma_{a}\right)}{\left[\sigma_{l}\left(1+\varepsilon_{c a}\right)+\sigma_{c}\right](z-1)} \widehat{m}_{t}
$$

which evidently exhibits an unstable root. Thus, one can uniquely determine end-ofperiod real balances $\widehat{m}_{t}$, current consumption $\widehat{c_{t}}$, the nominal interest rate $\widehat{R}_{t} \forall t \geq 0$, while inflation $\widehat{\pi}_{t}$ can only be determined for $t \geq 1$.

\section{References}

Benhabib, J., Schmitt-Grohé, S., and M. Uribe, 2001a, Monetary Policy and Multiple Equilibria, American Economic Review 91, 167-185.

Benhabib, J., Schmitt-Grohé, S., and M. Uribe, 2001b, The Perils of Taylor Rules, Journal of Economic Theory 96, 40-69.

Benhabib, J., Schmitt-Grohé, S., and M. Uribe, 2003, Backward-Looking InterestRate Rules, Interest Rate Smoothing, and Macroeconomic Instability, Journal of Money, Credit, and Banking 35, 1379-1412.

Bénassy, J.P., 2000, Price Level Determinacy under a Pure Interest Rate Peg, Review of Economic Dynamics 3, 194-211.

Blanchard, O.J., and C.M. Kahn, 1980, The Solution of Linear Difference Models under Rational Expectations, Econometrica 48, 1305-1313.

Brckner, M. and A. Schabert 2005, Can Money matter for Interest Rate Policy?, Journal of Economic Dynamics and Control (forthcoming). 
Brock, W.A., 1974, Money and Growth: The Case of Long Run Perfect Foresight, International Economic Review 15, 750-777.

Calvo, G., 1983, Staggered Prices in a Utility-Maximizing Framework, Journal of Monetary Economics 12, 383-398.

Carlstrom, C.T., and T.S. Fuerst, 2001, Timing and Real Indeterminacy in Monetary Models, Journal of Monetary Economics 47, 285-298.

Carlstrom, C.T., and T.S. Fuerst, 2003, Money Growth Rules and Price Level Determinacy, Review of Economic Dynamics 6, 263-275.

Carlstrom, C.T., and T.S. Fuerst, 2004, Investment and Interest Rate Policy: A Discrete Time Analysis, Journal of Economic Theory, forthcoming.

Clower, R.W., 1967, A Reconsideration of the Microfoundations of Monetary Theory, Western Economic Journal 6, 1-8.

Dupor, B., 2001, Investment and Interest Rate Policy, Journal of Economic Theory $98,85-113$.

Feenstra, R.C., 1986, Functional Equivalence between Liquidity Costs and the Utility of Money, Journal of Monetary Economics 17, 271-291.

Ireland, P.N. 2004, Money's Role in the Monetary Business Cycle, Journal of Money Credit and Banking, vol. 36, 969-983.

Ljungqvist, L., and T.J. Sargent, 2004, Recursive Macroeconomic Theory, 2. edition, Cambridge Massachusetts: The MIT Press.

Matsuyama, K., 1990, Sunspot Equilibria (Rational Bubbles) in a Model of Moneyin-the-Utility-Function, Journal of Monetary Economics 25, 137-144. 
Matsuyama, K., 1991, Endogenous Price Fluctuations in an Optimizing Model of the Monetary Economy, Econometrica 59, 1617-1631.

McCallum, B.T., and M. Goodfriend, 1987, Demand for Money: Theoretical Studies, in: The New Palgrave: A Dictionary of Economics, J. Eatwell, M. Milgate, and P. Newman (eds.), London: Macmillan, 775-781.

McCallum, B.T., and E. Nelson, 1999, An Optimizing IS-LM Specification for Monetary Policy and Business Cycle Analysis, Journal of Money, Credit, and Banking 31, 296-316.

Obstfeld, M., and K. Rogoff 1983, Speculative Hyperinflations in Maximizing Models: Can we rule them out?, Journal of Political Economy 91, 675-687.

Patinkin, D. 1949, The Indeterminacy of Absolute Prices in Classical Economic Theory, Econometrica 17, 1-27.

Patinkin, D. 1965, Money, Interest and Prices, 2. edition, New York: Harper and Row.

Persson, M., T. Persson and Lars.E.O. Svensson 2006, Time Consistency of Fiscal and Monetary Policy: A Solution, Econometrica 74, 193-212.

Schabert, A., and C. Stoltenberg, 2005, Money Demand and Macroeconomic Stability Revisited, ECB Working Paper Series No. 458.

Svensson, L.E.O., 1985, Money and Asset Prices in a Cash-in-advance Model, Journal of Political Economy 93, 919-944.

Taylor, J.B., 1993, Discretion versus Policy Rules in Practice, Carnegie-Rochester Conference Series on Public Policy 39, 195-214. 
Woodford, M., 1990, The Optimum Quantity of Money, in: Handbook of Monetary Economics, B.M. Friedman and F.H. Hahn (eds.), Amsterdam: North Holland.

Woodford, M., 2003, Interest and Prices: Foundations of a Theory of Monetary Policy, Princeton: Princeton University Press. 


\section{SFB 649 Discussion Paper Series 2006}

For a complete list of Discussion Papers published by the SFB 649, please visit http://sfb649.wiwi.hu-berlin.de.

001 "Calibration Risk for Exotic Options" by Kai Detlefsen and Wolfgang K. Härdle, January 2006.

002 "Calibration Design of Implied Volatility Surfaces" by Kai Detlefsen and Wolfgang K. Härdle, January 2006.

003 "On the Appropriateness of Inappropriate VaR Models" by Wolfgang Härdle, Zdeněk Hlávka and Gerhard Stahl, January 2006.

004 "Regional Labor Markets, Network Externalities and Migration: The Case of German Reunification" by Harald Uhlig, January/February 2006.

005 "British Interest Rate Convergence between the US and Europe: A Recursive Cointegration Analysis" by Enzo Weber, January 2006.

006 "A Combined Approach for Segment-Specific Analysis of Market Basket Data" by Yasemin Boztuğ and Thomas Reutterer, January 2006.

007 "Robust utility maximization in a stochastic factor model" by Daniel Hernández-Hernández and Alexander Schied, January 2006.

008 "Economic Growth of Agglomerations and Geographic Concentration of Industries - Evidence for Germany" by Kurt Geppert, Martin Gornig and Axel Werwatz, January 2006.

009 "Institutions, Bargaining Power and Labor Shares" by Benjamin Bental and Dominique Demougin, January 2006.

010 "Common Functional Principal Components" by Michal Benko, Wolfgang Härdle and Alois Kneip, Jauary 2006.

011 "VAR Modeling for Dynamic Semiparametric Factors of Volatility Strings" by Ralf Brüggemann, Wolfgang Härdle, Julius Mungo and Carsten Trenkler, February 2006.

012 "Bootstrapping Systems Cointegration Tests with a Prior Adjustment for Deterministic Terms" by Carsten Trenkler, February 2006.

013 "Penalties and Optimality in Financial Contracts: Taking Stock" by Michel A. Robe, Eva-Maria Steiger and Pierre-Armand Michel, February 2006.

014 "Core Labour Standards and FDI: Friends or Foes? The Case of Child Labour" by Sebastian Braun, February 2006.

015 "Graphical Data Representation in Bankruptcy Analysis" by Wolfgang Härdle, Rouslan Moro and Dorothea Schäfer, February 2006.

016 "Fiscal Policy Effects in the European Union" by Andreas Thams, February 2006.

017 "Estimation with the Nested Logit Model: Specifications and Software Particularities" by Nadja Silberhorn, Yasemin Boztuğ and Lutz Hildebrandt, March 2006.

018 "The Bologna Process: How student mobility affects multi-cultural skills and educational quality" by Lydia Mechtenberg and Roland Strausz, March 2006.

019 "Cheap Talk in the Classroom" by Lydia Mechtenberg, March 2006.

020 "Time Dependent Relative Risk Aversion" by Enzo Giacomini, Michael Handel and Wolfgang Härdle, March 2006.

021 "Finite Sample Properties of Impulse Response Intervals in SVECMs with Long-Run Identifying Restrictions" by Ralf Brüggemann, March 2006.

022 "Barrier Option Hedging under Constraints: A Viscosity Approach" by Imen Bentahar and Bruno Bouchard, March 2006.

\section{SFB 649, Spandauer Straße 1, D-10178 Berlin} http:/ / sfb649.wiwi.hu-berlin.de

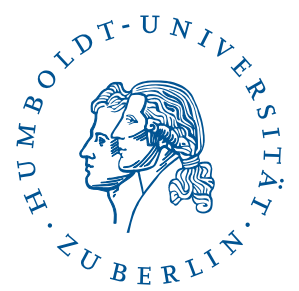


023 "How Far Are We From The Slippery Slope? The Laffer Curve Revisited" by Mathias Trabandt and Harald Uhlig, April 2006.

024 "e-Learning Statistics - A Selective Review" by Wolfgang Härdle, Sigbert Klinke and Uwe Ziegenhagen, April 2006.

025 "Macroeconomic Regime Switches and Speculative Attacks" by Bartosz Maćkowiak, April 2006.

026 "External Shocks, U.S. Monetary Policy and Macroeconomic Fluctuations in Emerging Markets" by Bartosz Maćkowiak, April 2006.

027 "Institutional Competition, Political Process and Holdup" by Bruno Deffains and Dominique Demougin, April 2006.

028 "Technological Choice under Organizational Diseconomies of Scale" by Dominique Demougin and Anja Schöttner, April 2006.

029 "Tail Conditional Expectation for vector-valued Risks" by Imen Bentahar, April 2006.

030 "Approximate Solutions to Dynamic Models - Linear Methods" by Harald Uhlig, April 2006.

031 "Exploratory Graphics of a Financial Dataset" by Antony Unwin, Martin Theus and Wolfgang Härdle, April 2006.

032 "When did the 2001 recession really start?" by Jörg Polzehl, Vladimir Spokoiny and Cătălin Stărică, April 2006.

033 "Varying coefficient GARCH versus local constant volatility modeling. Comparison of the predictive power" by Jörg Polzehl and Vladimir Spokoiny, April 2006.

034 "Spectral calibration of exponential Lévy Models [1]" by Denis Belomestny and Markus Reiß, April 2006.

035 "Spectral calibration of exponential Lévy Models [2]" by Denis Belomestny and Markus Reiß, April 2006.

036 "Spatial aggregation of local likelihood estimates with applications to classification" by Denis Belomestny and Vladimir Spokoiny, April 2006.

037 "A jump-diffusion Libor model and its robust calibration" by Denis Belomestny and John Schoenmakers, April 2006.

038 "Adaptive Simulation Algorithms for Pricing American and Bermudan Options by Local Analysis of Financial Market" by Denis Belomestny and Grigori N. Milstein, April 2006.

039 "Macroeconomic Integration in Asia Pacific: Common Stochastic Trends and Business Cycle Coherence" by Enzo Weber, May 2006.

040 "In Search of Non-Gaussian Components of a High-Dimensional Distribution" by Gilles Blanchard, Motoaki Kawanabe, Masashi Sugiyama, Vladimir Spokoiny and Klaus-Robert Müller, May 2006.

041 "Forward and reverse representations for Markov chains" by Grigori N. Milstein, John G. M. Schoenmakers and Vladimir Spokoiny, May 2006.

042 "Discussion of 'The Source of Historical Economic Fluctuations: An Analysis using Long-Run Restrictions' by Neville Francis and Valerie A. Ramey" by Harald Uhlig, May 2006.

043 "An Iteration Procedure for Solving Integral Equations Related to Optimal Stopping Problems" by Denis Belomestny and Pavel V. Gapeev, May 2006.

044 "East Germany's Wage Gap: A non-parametric decomposition based on establishment characteristics" by Bernd Görzig, Martin Gornig and Axel Werwatz, May 2006.

045 "Firm Specific Wage Spread in Germany - Decomposition of regional differences in inter firm wage dispersion" by Bernd Görzig, Martin Gornig and Axel Werwatz, May 2006.

\section{SFB 649, Spandauer Straße 1, D-10178 Berlin http:/ / sfb649.wiwi.hu-berlin.de}

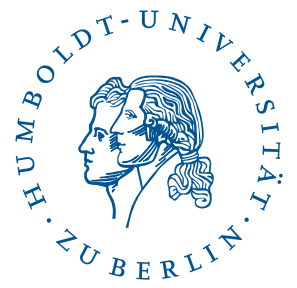


046 "Produktdiversifizierung: Haben die ostdeutschen Unternehmen den Anschluss an den Westen geschafft? - Eine vergleichende Analyse mit Mikrodaten der amtlichen Statistik" by Bernd Görzig, Martin Gornig and Axel Werwatz, May 2006.

047 "The Division of Ownership in New Ventures" by Dominique Demougin and Oliver Fabel, June 2006.

048 "The Anglo-German Industrial Productivity Paradox, 1895-1938: A Restatement and a Possible Resolution" by Albrecht Ritschl, May 2006.

049 "The Influence of Information Costs on the Integration of Financial Markets: Northern Europe, 1350-1560" by Oliver Volckart, May 2006.

050 "Robust Econometrics" by Pavel Čížek and Wolfgang Härdle, June 2006.

051 "Regression methods in pricing American and Bermudan options using consumption processes" by Denis Belomestny, Grigori N. Milstein and Vladimir Spokoiny, July 2006.

052 "Forecasting the Term Structure of Variance Swaps" by Kai Detlefsen and Wolfgang Härdle, July 2006.

053 "Governance: Who Controls Matters" by Bruno Deffains and Dominique Demougin, July 2006.

054 "On the Coexistence of Banks and Markets" by Hans Gersbach and Harald Uhlig, August 2006.

055 "Reassessing Intergenerational Mobility in Germany and the United States: The Impact of Differences in Lifecycle Earnings Patterns" by Thorsten Vogel, September 2006.

056 "The Euro and the Transatlantic Capital Market Leadership: A Recursive Cointegration Analysis" by Enzo Weber, September 2006.

057 "Discounted Optimal Stopping for Maxima in Diffusion Models with Finite Horizon" by Pavel V. Gapeev, September 2006.

058 "Perpetual Barrier Options in Jump-Diffusion Models" by Pavel V. Gapeev, September 2006.

059 "Discounted Optimal Stopping for Maxima of some Jump-Diffusion Processes" by Pavel V. Gapeev, September 2006.

060 "On Maximal Inequalities for some Jump Processes" by Pavel V. Gapeev, September 2006.

061 "A Control Approach to Robust Utility Maximization with Logarithmic Utility and Time-Consistent Penalties" by Daniel Hernández-Hernández and Alexander Schied, September 2006.

062 "On the Difficulty to Design Arabic E-learning System in Statistics" by Taleb Ahmad, Wolfgang Härdle and Julius Mungo, September 2006.

063 "Robust Optimization of Consumption with Random Endowment" by Wiebke Wittmüß, September 2006.

064 "Common and Uncommon Sources of Growth in Asia Pacific" by Enzo Weber, September 2006.

065 "Forecasting Euro-Area Variables with German Pre-EMU Data" by Ralf Brüggemann, Helmut Lütkepohl and Massimiliano Marcellino, September 2006.

066 "Pension Systems and the Allocation of Macroeconomic Risk" by Lans Bovenberg and Harald Uhlig, September 2006.

067 "Testing for the Cointegrating Rank of a VAR Process with Level Shift and Trend Break" by Carsten Trenkler, Pentti Saikkonen and Helmut Lütkepohl, September 2006.

068 "Integral Options in Models with Jumps" by Pavel V. Gapeev, September 2006.

069 "Constrained General Regression in Pseudo-Sobolev Spaces with Application to Option Pricing" by Zdeněk Hlávka and Michal Pešta, September 2006.

\section{SFB 649, Spandauer Straße 1, D-10178 Berlin} http:/ / sfb649.wiwi.hu-berlin.de

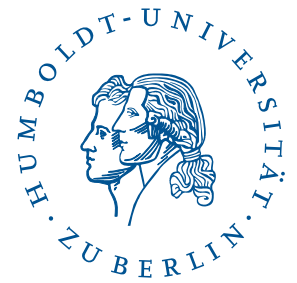


070 "The Welfare Enhancing Effects of a Selfish Government in the Presence of Uninsurable, Idiosyncratic Risk" by R. Anton Braun and Harald Uhlig, September 2006.

071 "Color Harmonization in Car Manufacturing Process" by Anton Andriyashin, Michal Benko, Wolfgang Härdle, Roman Timofeev and Uwe Ziegenhagen, October 2006.

072 "Optimal Interest Rate Stabilization in a Basic Sticky-Price Model" by Matthias Paustian and Christian Stoltenberg, October 2006.

073 "Real Balance Effects, Timing and Equilibrium Determination" by Christian Stoltenberg, October 2006. 